\title{
Clausura de la última campaña de la Agencia Europea para la Seguridad y la Salud en el Trabajo
}

\author{
Rosa Maria Orriols Ramos $1,2,3$ \\ Mari Cruz Rodríguez-Jareño $0^{1,4,5}$ \\ 'Societat Catalana de Salut Laboral, Barcelona, España y Sociedad Española de Medicina y Seguridad \\ en el Trabajo. \\ 2Servicio de Prevención de Hospital Universitari Bellvitge, Institut Català de la Salut, Barcelona. Espa- \\ ก̃a. \\ ${ }^{3}$ Junta Directiva de International Commission Occupational Health. \\ ${ }^{4}$ Servicio de Prevención de SSIBE_Fundación Hospital de Palamós, Palamós (Girona). España \\ ${ }^{5}$ Departamento de Ciencias Médicas, Facultad de Medicina, Universitat de Girona, Girona. España
}

Información · Information

Este documento es resultado de las actividades de la Sección de Medicina del Trabajo de la UEMS (Unión Europea de Médicos Especialistas: www.uems.net)

Fechas · Dates

Recibido: 2019.12 .27

Publicado: 2020.01.15
Correspondencia $\cdot$ Corresponding Author

Mari Cruz Rodríguez-Jareño

mcrodriguezj@gmail.com 
La clausura de la última campaña de la Agencia Europea para la Seguridad y la Salud en el Trabajo para la Seguridad y la Salud en el Trabajo tuvo lugar el 12 y 13 de noviembre de 2019 en Bilbao.

A la clausura de la campaña asistieron Rosa Orriols en representación de ICOH (Rosa es miembro de la Junta Directiva de ICOH), y Mari Cruz Rodríguez-Jareño en representación de la UEMS, que fue uno de los 90 socios oficiales de la campaña (Mari Cruz es la representante española en la UEMS a través de la SEMST y la SCSL). Ambas pertenecen a la Junta de la SCSL.

La campaña que se clausuraba (2018-2019) estuvo dedicada a las substancias químicas peligrosas, siendo el lema: «Trabajos saludables: alerta frente a sustancias peligrosas «. Además la Agencia este año 2019 celebraba su 25 aniversario.

Durante la reunión, expertos europeos y responsables en toma de decisiones discutieron los resultados de la campaña de dos años, compartieron conocimientos y exploraron estrategias para la prevención efectiva y el manejo sostenible de sustancias peligrosas en los lugares de trabajo en el futuro.

Tras la presentación inicial de la presidenta de la Agencia, Christa Sedlatschek, se dio paso a talleres paralelos que analizaron las actividades de prevención de carcinógenos en el trabajo, las buenas prácticas en el sector de servicios, y la sustitución de sustancias peligrosas en los procesos de producción. También se discutieron las medidas de seguridad y salud en el trabajo más efectivas con respecto a los usos de productos químicos en el futuro.

A continuación, se hizo entrega de los Premios a las buenas prácticas en lugares de trabajo saludables a las diez organizaciones elegidas por un jurado internacional independiente, premiando su enfoque proactivo y participativo para el manejo de sustancias peligrosas.

Las principales conclusiones de los talleres paralelos se presentaron en sesión plenaria así como una mesa de discusión sobre «Substancias peligrosas: lecciones del pasado para el futuro».

Finalmente se cerró el encuentro con la presentación de la próxima Campaña de lugares de trabajo saludables que a partir de ahora tendrán una duración de 3 años.

La campaña 2020-22 «Trabajos saludables: aliviemos las cargas» comenzará a ejecutarse en octubre de 2020 y estará dedicada a aumentar la conciencia sobre la importancia de prevenir los trastornos musculoesqueléticos relacionados con el trabajo.

Los riesgos relacionados con las posturas y la exposición a movimientos repetitivos son factores de riesgo muy habituales en el lugar de trabajo que pueden provocar trastornos músculoesqueléticos, que siguen siendo uno de los problemas de salud con mayor prevalencia en Europa. 
La campaña tiene por objeto divulgar información de alta calidad en la materia, fomentar un enfoque integrado en la gestión del problema, y ofrecer herramientas y soluciones prácticas que sirvan de ayuda en el lugar de trabajo.

Agencia Europea para la Seguridad y la Salud en el Trabajo: https://osha.europa.eu/ es

ICOH: International Commission on Occupational Health: http://www.icohweb.org/ site/homepage.asp

UEMS: Union of European Medical Specialists: https://uems-occupationalmedicine. org/

SEMST: Sociedad Española de Medicina y Seguridad en el Trabajo: https://www. semst.org/

SCSL: Societat Catalana de Salut Laboral: http://www.salutlaboral.com/

\section{Cloenda de l'última campanya de l'Agència Europea per la Seguretat i la Salut en el Treball}

La cloenda de l'última campanya de l'Agència Europea per la Seguretat i la Salut en el Treball va tenir lloc el 12 i 13 de novembre de 2019 a Bilbao.

A la cloenda de la campanya van assistir Rosa Orriols en representació de ICOH (Rosa és membre de la Junta Directiva d'ICOH), i Mari Cruz Rodríguez-Jareño en representació de la UEMS, que va ser un dels 90 socis oficials de la campanya (Mari Cruz és la representant espanyola en la UEMS a través de la SEMST i la SCSL). Totes dues pertanyen a la Junta de la SCSL.

La campanya que es clausurava (2018-2019) va estar dedicada a les substàncies químiques perilloses, essent el lema: «Treballs saludables: alerta davant de substàncies perilloses». A més l'Agència aquest any 2019 celebrava el seu 25 aniversari.

Durant la reunió, experts europeus i responsables en presa de decisions van discutir els resultats de la campanya de dos anys, van compartir coneixements i van explorar estratègies per a la prevenció efectiva i el maneig sostenible de substàncies perilloses en els llocs de treball en el futur.

Després de la presentació inicial de la presidenta de l'Agència, Christa Sedlatschek, es va donar pas a tallers paral.lels que van analitzar les activitats de prevenció de carcinògens en el treball, les bones pràctiques en el sector de serveis, i la substitució de substàncies perilloses en els processos de producció. També es van discutir les mesures de seguretat i salut en el treball més efectives pel que fa als usos de productes químics en el futur. 
A continuació, es va fer entrega dels Premis a les bones pràctiques en llocs de treball saludables a les deu organitzacions triades per un jurat internacional independent, premiant el seu enfocament proactiu i participatiu per al maneig de substàncies perilloses.

Les principals conclusions dels tallers paral·lels es van presentar en sessió plenària així com una taula de discussió sobre «Substàncies perilloses: Iliçons del passat per al futur».

Finalment es va tancar la trobada amb la presentació de la propera Campanya de llocs de treball saludables que a partir d'ara tindran una durada de 3 anys.

La campanya 2020-22 «Treballs saludables: alleugerim les càrregues» començarà a executar-se a l'octubre de 2020 i estarà dedicada a augmentar la consciència sobre la importància de prevenir els trastorns musculoesquelètics relacionats amb el treball.

Els riscos relacionats amb les postures i l'exposició a moviments repetitius són factors de risc molt habituals en el lloc de treball que poden provocar trastorns músculoesqueléticos, que segueixen sent un dels problemes de salut amb més prevalença a Europa.

La campanya té per objecte divulgar informació d’alta qualitat en la matèria, fomentar un enfocament integrat en la gestió del problema, i oferir eines i solucions pràctiques que serveixin d'ajuda en el lloc de treball.

Agència Europea per la Seguretat i la Salut en el Treball: https://osha.europa.eu/es ICOH: International Commission on Occupational Health: http://www.icohweb.org/ site/homepage.asp

UEMS: Union of European Medical Specialists: https://uems-occupationalmedicine. org/

SEMST: Sociedad Española de Medicina y Seguridad en el Trabajo: https://wWW. semst.org/

SCSL: Societat Catalana de Salut Laboral: http://www.salutlaboral.com/ 